\title{
BMJ Open Cost-effectiveness research in cancer therapy: a systematic review of literature trends, methods and the influence of funding
}

\author{
Daoud Al-Badriyeh, ${ }^{1}$ Marwah Alameri, ${ }^{2}$ Randa Al-Okka ${ }^{3}$
}

To cite: Al-Badriyeh D, Alameri M, Al-Okka R. Costeffectiveness research in cancer therapy: a systematic review of literature trends, methods and the influence of funding. BMJ Open 2017;7: e012648. doi:10.1136/ bmjopen-2016-012648

- Prepublication history and additional material is available. To view please visit the journal (http://dx.doi.org/ 10.1136/bmjopen-2016012648).

Received 16 May 2016 Revised 13 November 2016 Accepted 14 December 2016

\section{(D) CrossMark}

${ }^{1}$ College of Pharmacy, Qatar University, Doha, Qatar ${ }^{2}$ School of Pharmacy, University College London, London, UK

${ }^{3}$ National Center for Cancer Care and Research, Hamad Medical Corporation, Doha, Qatar

Correspondence to Dr Daoud Al-Badriyeh; daoud.a@qu.edu.qa

\section{ABSTRACT}

Objective: To perform a first-time analysis of the cost-effectiveness (CE) literature on chemotherapies, of all types, in cancer, in terms of trends and change over time, including the influence of industry funding.

Design: Systematic review.

Setting: A wide range of cancer-related research settings within healthcare, including health systems, hospitals and medical centres.

Participants: All literature comparative CE research of drug-based cancer therapies in the period 1986 to 2015.

\section{Primary and secondary outcome measures:}

Primary outcomes are the literature trends in relation to journal subject category, authorship, research design, data sources, funds and consultation involvement. An additional outcome measure is the association between industry funding and study outcomes.

Analysis: Descriptive statistics and the $\chi^{2}$, Fisher exact or Somer's $D$ tests were used to perform nonparametric statistics, with a $p$ value of $<0.05$ as the statistical significance measure.

Results: Total 574 publications were analysed. The drug-related CE literature expands over time, with increased publishing in the healthcare sciences and services journal subject category $(p<0.001)$. The retrospective data collection in studies increased over time $(p<0.001)$. The usage of prospective data, however, has been decreasing $(p<0.001)$ in relation to randomised clinical trials (RCTs), but is unchanging for non-RCT studies. The industry-sponsored CE studies have especially been increasing $(p<0.001)$, in contrast to those sponsored by other sources. While paid consultation involvement grew throughout the years, the declaration of funding for this is relatively limited. Importantly, there is evidence that industry funding is associated with favourable result to the sponsor $(p<0.001)$.

Conclusions: This analysis demonstrates clear trends in how the CE cancer research is presented to the practicing community, including in relation to journals, study designs, authorship and consultation, together with increased financial sponsorship by pharmaceutical industries, which may be more influencing study outcomes than other funding sources.

\section{Strengths and limitations of this study}

- This is the first literature audit of the costeffectiveness research in cancer therapy, which reported important characteristics in relation to journals, study designs, authorship, consultation and funds.

- The study includes all relevant journals, over 30 years of follow-up.

- The study is the first comprehensive analysis of the association between industry funding and results of economic studies on chemotherapies use, of all types, in cancer.

- The literature search is language restricted.

- Although all journals were weighted equally in relation to the quality of their publications, it is anticipated that potential bias and confounding is minimised due to the thorough and diverse types of included studies.

\section{BACKGROUND}

Cancer is a leading worldwide health problem, with $\sim 14$ million recorded new cases in a year. ${ }^{1}$ In the USA, for example, over 0.5 million people die from cancer each year, making cancer the number 2 cause of death there. ${ }^{2}$ Important is the fact that the cancer prevalence has generally been increasing, mostly due to the increasing lifespan of people. While recent lifestyle changes have an impact on the spread of cancers, about two-thirds of the increase in cancer is due to longevity. More than three-quarters of all people diagnosed with cancer in the UK, for example, are over the age of $60 .^{3}$

Added to the increasing cancer prevalence, there are several reasons that currently lead to an increase in the cancer therapy market. These include the availability and high development cost of better immunotherapy agents, the non-curable and serious nature of most cancers, the reduced competition among agents as the use of an agent 
does not preclude from the concurrent/subsequent use of another, that cheaper generics are often not considered as available alternatives to newer more costly agents but they are replaced by them, the earlier diagnoses and increased chronic management, the lack of magnitude threshold of drug benefit and increased insurance premiums due to unpredictable disease status. ${ }^{4}$ Between the years 2007 and 2013 for instance, the global cancer therapy market more than doubled, increasing from USD40 billion to over 110 billion in 2013. This is a high annual growth rate of over $18 \%$. Looking at the targeted therapy separately, which constitutes $45 \%$ of the cancer therapy market, this about tripled in within the same duration, increasing from combined market cost value of about US $\$ 22$ billion to almost 70 billion. $^{5}$

There are ethical issues surrounding the comparative research on newer therapies for a dangerous disease like cancer, particularly the prospective research, which generally stem from the fact that exposing study participants to increased risk with experimental therapies may not actually be counterbalanced by clinical benefit. In comparative research, participants may, for example, be harmed by receiving a placebo instead of an active treatment or, more commonly, participants stand the chance of receiving an experimental cancer therapy that will eventually turn out to be inferior to the best usual therapy available to patients. This is ethically problematic, given the recognised ethical principle that patients should receive the best proven standard of care whenever feasible.

In any case, apart from any controversies regarding conducting comparative clinical research on the newer cancer therapies, one defining feature of the latter is that they are substantially more expensive than the traditional therapies. ${ }^{6}$ Here, in recent years, there has been a significant worldwide focus on payers and governmental agency policies to contain spending on cancer by the pharmacoeconomics research, with the cost-effectiveness (CE) analysis (CEA) being the most common. Within the evidence-based medicine therefore, the size of the CEA literature in cancer is anticipated to have increased, particularly in the last decade. Nevertheless, despite recognised importance of the CEA literature on chemotherapies and its role in practice, there is a literature gap concerning how this research field has evolved over the years, in relation to characteristics and the trends in scientific publications. Also, previous research has found that industry-funded economic studies tend to favour the sponsors' cancer therapies. These, however, were limited in the types of therapy, cancer or methods used (vide infra). The growth of the industry authorship and/ or funding in the economics research cancer therapy is also not described in the literature. This is important as maintaining balanced funding of economic analyses from other sources may be required to allow greater confidence in the interpretation of results. ${ }^{7-10}$

Within the context of CEA research on all types of cancer chemotherapies, the current study is a thorough audit that sought to answer questions in relation to (1) characteristics of research and scientific publications, (2) trends overtime and (3) the spread of pharmaceutical industry involvement and its potential influence on study outcomes.

With the lack of research method standardisation and a typical lack of compliance with established standards, answers to the study questions in relation to the literature characteristics and trends will be of practical value to researchers in planning and organising their research, journal editors and reviewers in enhancing the quality of published research, and also the decision makers in better understanding a quality of evidence as they contrast this against current strengths and weaknesses of methods in the literature.

\section{METHODS}

This study is a systematic audit, involving all drug-related cancer CEA studies that were published in all English-language medical literature over 30 years (1 January 1986 to 31 December 2015).

\section{Literature review}

Studies were identified via the PubMed, Embase and EconLit search engines. Screening for initial eligibility was by assessing the title and abstract first. The second screening for eligibility was by the review of the full text of manuscripts. This was performed twice, each by one of the authors 'MA' and 'RA-O' independently. In the case of disagreement, consensus was achieved by discussion with the third author 'DA-B'. Full-text articles that are not freely available were retrieved via the Qatar University library. ${ }^{11}$

The PubMed index terms used were the MeSH terms 'Cost-Benefit Analysis' and 'Neoplasms'. The 'CostBenefit Analysis' MeSH term includes a variety of entry terms, including the cost-effectiveness, cost-utility, costbenefit and economic evaluation(s). The 'Neoplasms' $\mathrm{MeSH}$ term includes a variety of relevant entry terms, including cancer(s), tumor(s) and neoplasm. The Embase index terms used were the Emtree terms 'cost effectiveness', 'cost benefit', 'cost utility', 'cost minimization', 'economic evaluation', 'cost', 'pharmacoeconomics', 'neoplasm', 'neoplasms', 'cancer', 'cancers' and 'tumor', in addition to the term 'tumors'. The EconLit search terms were 'cost effectiveness', 'cost utility', 'cost benefit', 'economic evaluation', 'neoplasm', 'cancer' and 'tumor'. The search strategy shown in online supplementary appendix 1 was used for PubMed, and this was adapted for other databases.

\section{Inclusion and exclusion criteria}

The inclusion criteria are:

- Publication between 1 January 1986 and 31 December 2015.

- Drug therapy-based comparative study.

- Cancer-based underlying disease.

- CE evaluation. 
These involve retrospective and prospective research, and no considerations were made of whether articles were freely available. Via the different search databases used, search included grey literature, such as books, dissertations, conferences, working papers and government publications.

The exclusion criteria are:

- Non-English language.

- Non-human studies.

- Non-comparative research, for example, letters, editorials and general reviews.

- Non-drug relevant studies.

\section{DEFINITIONS}

The drug therapy was defined as any chemical used as curative, adjunct, palliative or maintenance chemotherapy in a cancer-related disease. This can be evaluated against a drug, procedure and/or placebo. While the use of placebos in randomised clinical trials (RCTs) of cancer is controversial, it can be justified in cases such as when the stability of a tumour is the targeted effect when compared with shrinkage, whereby a tumour may naturally not grow without treatment. This is added to cases where reduced side effects with newer molecularly targeted therapies are hard to distinguish from the cancer effect. In any case, placebos are only acceptable if no effective therapy is available and that patients on placebos receive the top concurrent supportive care. ${ }^{12}$

Industry involvement was defined as having a pharmaceutical industry (organisations) that is responsible for the funding of the study.

Industry involvement in the authorship was also assessed in this study, including that occurring through consultation firms.

Study publications were mainly classified according to:

- Journal subject category; haematology/oncology, medicine, pharmacology and pharmacy, healthcare sciences and services.

- The haematology/oncology category in this classification is used to include the haematology and oncology subject categories.

- The medicine category in this classification is used to include several categories relating to any journal that is of a subject category concerning the subject of medicine, including those relevant to specific body systems as subject categories.

- There is no journal discipline of pharmacoeconomics that officially exists. Nevertheless, for the purpose of this study, a comparative pharmacoeconomics category of journals was created, which included journals (from across all subject categories) that have announced especial interest in publishing pharmacoeconomics research as part of their scope.

- The journal that is classified under more than one subject category was considered under the subject category where it was ranked the highest (based on impact factor) relative to the other journals in the category.
- Information about subject categories of journals was obtained from the 2013 Journal Citation Report, by the ISI Web of Knowledge database, via Qatar University library. ${ }^{11}$

- Method of research; retrospective (non-RCT or meta-analysis) that does not rely on published RCT data and is based on other historical resources, for example, medical records, prospective (non-RCT or meta-analysis) that does not rely on RCT data and is based on other prospective resources, for example, prospective medical record data, RCTs (retrospective) that relies mostly on extracted data from already published RCTs, RCTs (prospective) that relies mostly on prospectively extracted data from ongoing RCTs, meta-analysis (retrospective or prospective).

- Source of funding; not declared, non-profit, pharmaceutical industry, combination of non-profit and pharmaceutical industry.

- While we documented any provision of the study drug by a sponsor/manufacturer, this was not solely considered to constitute a study sponsorship. For studies with non-declared sponsor, an industry funding source was assumed if the study drug supplies were provided by, and one or more authors were affiliated with, that particular pharmaceutical sponsor.

- Coauthorship affiliation; patentee (manufacturer), consultation firm, non-profit.

- The status of authorship was achieved if one or more study authors were affiliated with the organisation. This does not include potential conflict of interest due to relationship with an organisation, that is, personal funding, consultation role.

- Declaration of details of potential conflict of interest; there is a conflict, there is no conflict and not indicated.

- The comparative arm to the study drug; alternative drug, procedure, placebo.

- Reported study outcome; outcome is in favour of the study drug over control (positive outcome), study drug is equivalent to control, outcome is in favour of control over study drug (negative outcome).

- Outcomes in the CEA studies are related to the CE ratio, cost saving and the dominance status. The size of the outcome difference was not taken in consideration. This is due to the relative nature of the economic outcomes (and their importance), and the lack of a standardised tool to assess this.

\section{DATA COLLECTION AND STATISTICAL ANALYSIS}

Authors completed data collection, populating a 33-variable database. Of these, the variables that are most relevant to the analysis are listed in table 1.

Data were grouped into five 6-year periods (blocks) for analysis and presentation purposes.

For validation purposes, while two authors shared data collection, the third author reviewed the extraction (and database population) of the relevant data 
Table 1 Study database variables

\begin{tabular}{ll}
$\begin{array}{l}\text { Journal title } \\
\text { Journal subject category }\end{array}$ & $\begin{array}{l}\text { Author affiliation with } \\
\text { patentee, with known } \\
\text { sponsor or non-profit } \\
\text { funding }\end{array}$ \\
$\begin{array}{l}\text { Journal year } \\
\text { Block (6-year period) }\end{array}$ & $\begin{array}{l}\text { patentee, with unknown } \\
\text { sponsor }\end{array}$ \\
number & Authors affiliated with a \\
& consultation company \\
Sumber of coauthors with & affiliation with consultation \\
employed & companies \\
Study comparator & Author affiliated with a \\
Study outcome & consultation company, with \\
Declaration of potential & sponsor known \\
conflict of interest & Author affiliated with a \\
Funding source & consultation company, with \\
Non-profit authorship & sponsor unknown \\
Number of authors with & Author affiliation with \\
affiliation with patentee, & sponsor and/or source of \\
including all company & drug supplies \\
authors & \\
\hline
\end{tabular}

from each included article. Disagreements, including in relation to miscoding, were further discussed until consensus. Also, randomly selected $10 \%$ sample of the included articles had undergone a repeat audit, in relation to the study outcomes, by an institutional research assistant in pharmacoeconomics, in addition to the pharmacoeconomist author (DA-B). The agreement of the latter was of a $98 \%$.

Descriptive statistics were used to measure distribution of variables, and cross tabulation was used to provide information about comparison of frequency data. $\chi^{2}$, Fisher exact test or Somer's D test was used to measure the difference and association. Significance was set at a $\mathrm{p}$ value of $<0.05$. Data collection, entry and analyses were performed using SPSS-22.

The PRISMA and AMSTAR reporting checklists have been completed for the purpose of the current systematic review as shown in online supplementary appendices 2 and 3, respectively.

\section{QUALITY ASSESSMENT}

To further understand the changes in study variables overtime, the quality of economic studies was assessed over the study time blocks as a potential confounding factor. To isolate the effect of variations in the study quality on differences in study outcomes under different funding sources, the quality of studies as per the funding source was also reported. The quality of studies was evaluated and scored via the use of the Quality of Health Economics Studies (QHES) checklist. The quality assessment was independently conducted by different individual researchers, as described above under the literature review. Since no standardisation exists for the interpretation of QHES scores, the score 75-100 was set as good, the score $51-74$ as fair, the score $25-49$ as poor and the score $0-24$ as extremely poor. ${ }^{13-15}$

\section{RESULTS}

The literature search generated 574 publications that met the inclusion criteria in the current study (figure 1). The number of included publications is $9,41,82,124$ and 318 in the blocks 1986-1991, 1992-1997, 1998-2003, 20042009 and 2010-2015, respectively. This is out of 116, 411, 926, 1323 and 2573 found articles in relation to economics of cancer in the study blocks, respectively.

\section{Journal subject categories}

Most of the cancer-related CEA studies were published in journals that are in the haematology/oncology subject category $(n=210)$. This is followed by publications in the journals that relate to medical subject categories $(n=159)$. Those that are published in the healthcare sciences and services journals were 153 . Only 52 CEA studies were published in the pharmacy category of journals.

As discussed above, there is no subject category of pharmacoeconomics that officially exists. But when looking at journals across all disciplines, which have announced special interest in publishing pharmacoeconomics research, 146 CEA studies were reported. Based on the analysed CEA literature in this study, the journals in the pharmacoeconomics journal category were: Clinical Therapeutics, Health Technology and Assessment, Pharmacoeconomics, Clinical Drug Investigation, Current Medical Research Opinion, Value in Health, European Journal of Health Economics and ClinicoEconomics and Outcomes Research.

During 1986-1991, the percentage of contribution of the medical subject category in the literature was more

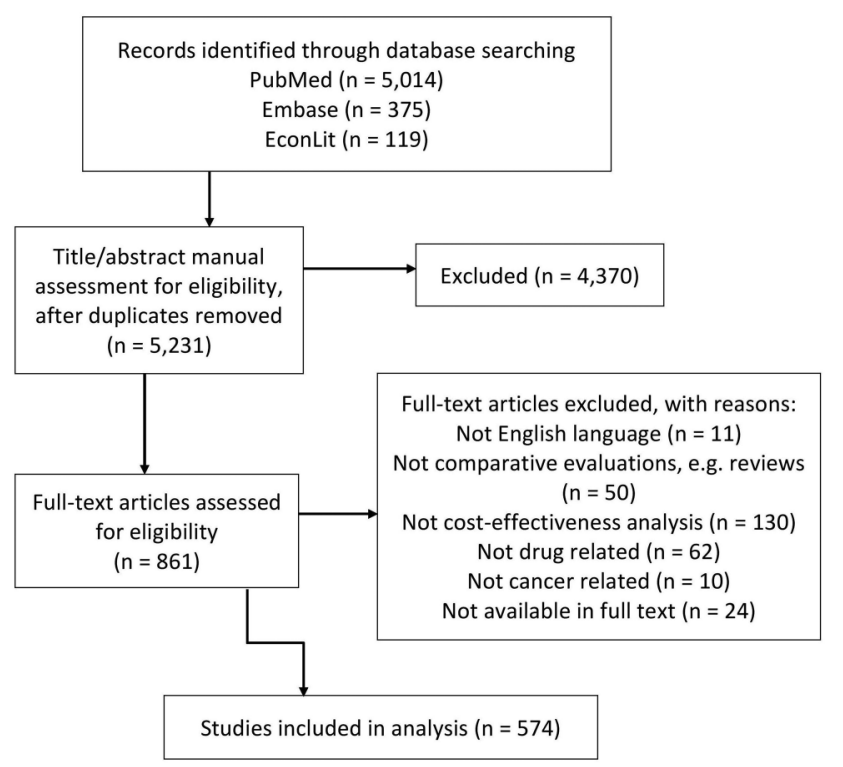

Figure 1 Flow diagram of studies inclusion and exclusion. 
than any other journal category. From 1992 onwards, however, this contribution exhibited a statistically significant decrease $(p<0.001)$. The contribution of the haematology/oncology category also statistically changed over the 30 years period, with its percentage contribution peaking during 1998-2003. Interestingly, this is immediately preceding the time point when the health sciences and services category of journals started to show contribution in the literature, drastically increasing afterwards until becoming the journal category that contributed the most to the literature in $2015(41.2 \%, \mathrm{p}<0.001)$. The contribution of pharmacy subject category in the literature did not change over the years, it always had the least literature share among the contributing journal categories. The distribution of cancer CEA studies among the different journal subject categories is shown in figure 2A. The publications in the pharmacoeconomics journal category consistently increased over time $(p<0.001)$. These increased to constitute $30.8 \%$ of the overall relevant literature by 2015 .

\section{Research methodology employed}

The vast majority of CEA studies were retrospective in nature; involving 198 studies that are retrospective (but non-RCT or meta-analysis), and 189 studies that are based on retrospective RCT data. Prospective RCT studies were 98 in number. This is higher than the number of prospective studies that were not RCT or
Figure 2 Published studies according to journal subject category $(A)$, study design (B) and funding source $(\mathrm{C})$.
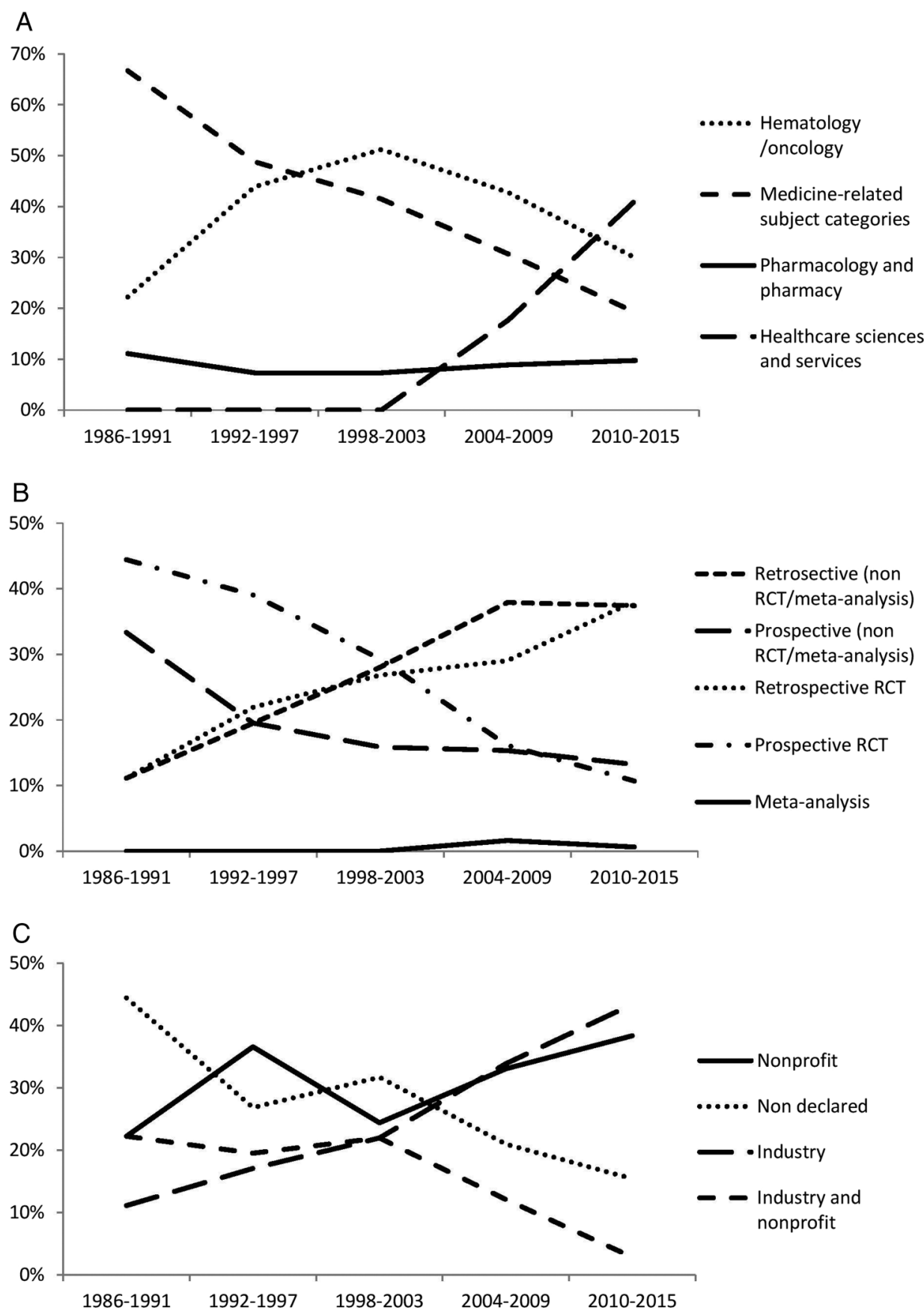
meta-analysis $(\mathrm{n}=85)$. Only four studies used meta-analysis evaluation, and these were retrospective in nature.

There is an overall increasing trend over time in relation to the use of the retrospective study design $(p<0.001)$. The usage of the prospective RCT data, however, demonstrated a statistically significant decrease $(\mathrm{p}<0.001)$. This was not the case with the prospective studies that were not RCT or meta-analysis, where the contribution did not statistically change over time $(\mathrm{p}=0.418)$. All the meta-analysis-based publications were reported after 2004. Utilisation trends of the different CEA study designs in the literature on cancer can be seen in figure $2 \mathrm{~B}$.

Table 2 shows the names of the journals that included $\geq 5 \%$ of the publications in each respective category. This includes the journals that have special scope for pharmacoeconomics research.

\section{Study funding}

Over the study period, the source of funding was as follows: not declared in 116 studies, a non-profit organisation in 200 studies and the pharmaceutical industry in 206 studies. A mixed funding jointly by non-profit organisations and the pharmaceutical industry was reported in 52 studies.

Relative to other types of funding, the industry funding demonstrated a significant increase over time $(p<0.001)$. Although not statistically significant over time $(\mathrm{p}=0.162)$, the percentage of contribution increased with non-profit organisations funding. The contribution, however, significantly decreased with non-declared and mixed type of funding $(\mathrm{p} \leq 0.003)$. Figure 2C demonstrates the different trends of the studies funding.

\section{Study drugs}

In most of the study publications $(n=347)$, the study drug was compared with alternative medications. A procedure was used as the comparator for the study drug in 71 studies only, while in 156 studies, this was a placebo.

\section{Drug supply by company}

The study drug was supplied by the drug manufacturer in only 61 of studies. In the majority of the studies, that is, the remaining 513 studies, the source of the study drug was not the manufacturer or was not declared.

\section{Authorship}

Coauthorship that is affiliated with pharmaceutical companies and consultation firms has increased in number over time, to a total of 89 and 61 , respectively. While this was not a statistically significant trend for the authorship by consultation firms $(p=0.627)$, it was for the authorship by pharmaceutical companies $(p=0.019)$. It is worth noting that the gap size between the two authorships decreased over time. The number of authorships in the follow-up blocks is 2 vs 0,12 vs 5,17 vs 9,21 vs 14 and 37 vs 33, respectively. Also observed is that in $26 \%$ of the publications with paid consultation involvement, the

Table 2 Cost-effectiveness publications according to subject categories journals

\section{Subject category \\ Oncology/haematology}

Medicine

Pharmacy

Healthcare sciences and services

Pharmacoeconomics
Journal (ranked ascendingly, in within each subject category, according to contribution in the literature)

Journal of Clinical Oncology

Annals of Oncology

British Journal of Cancer

Cancer

Breast Cancer Research and Treatment

European Journal of Cancer

Acta Oncologica

Oncology

Support Care Cancer

Lung Cancer*

Current Medical Research and Opinion

Clinical Therapeutics

Clinical Drug Investigation

Pharmacoeconomics*

Value in Health

ClinicoEconomics and Outcomes Research

Health Technology Assessment

Pharmacoeconomics

Value in Health

Clinical Therapeutics

ClinicoEconomics and Outcomes Research

Health Technology Assessment

Clinical Drug Investigation

*Journals that have classifications under multiple subject categories. 
study sponsor was unknown, which did not change ( $\mathrm{p}=0.403)$ over the years.

Throughout the literature, 120 of the studies reported a conflict of interest, 151 studies did not declare whether a conflict of interest existed and most of the studies reported that no conflict of interest existed $(n=303)$. The rate of the lack of conflict of interest declaration statistically decreased over the years $(p<0.001)$.

\section{Study outcomes and association with the funding source}

A positive outcome in favour of the study drug was reported in 420 studies, 80 studies reported an outcome that is in favour of the comparator intervention, and 74 studies indicated equivalent study interventions.

Taking the funding source in consideration, while the non-declared and non-profit organisation funding was statistically associated with a positive reported intervention outcome ( $\mathrm{p}=0.046$ and 0.007 , respectively), a comparatively stronger evidence of a statistically significant association existed between sole industry funding and reported outcomes of sponsored-drug studies $(\mathrm{p}<0.001$, ie, 0.000005$)$. As seen in figure 3 , in $95.1 \%$ of the industry-sponsored studies (196 out of 206 industryfunded studies), outcomes were in favour of the sponsored drug. This is statistically different from studies funded by the industry and when a non-profit organisation funding is involved (mixed types of sponsorships), where no evidence of association with favourable outcomes existed $(\mathrm{p}=0.134)$.

\section{Quality assessment}

Results of the quality assessment as per the time blocks and sources of study funding can be seen in table 3 .

\section{DISCUSSION}

This is the first report to characterise the literature on $\mathrm{CE}$ in relation to cancer therapies. The number of studies has rapidly grown, by over 30 folds between 1986 and 2015. This is not surprising because increasingly insufficient financial resources, health economics and, particularly, the pharmacoeconomics analyses are

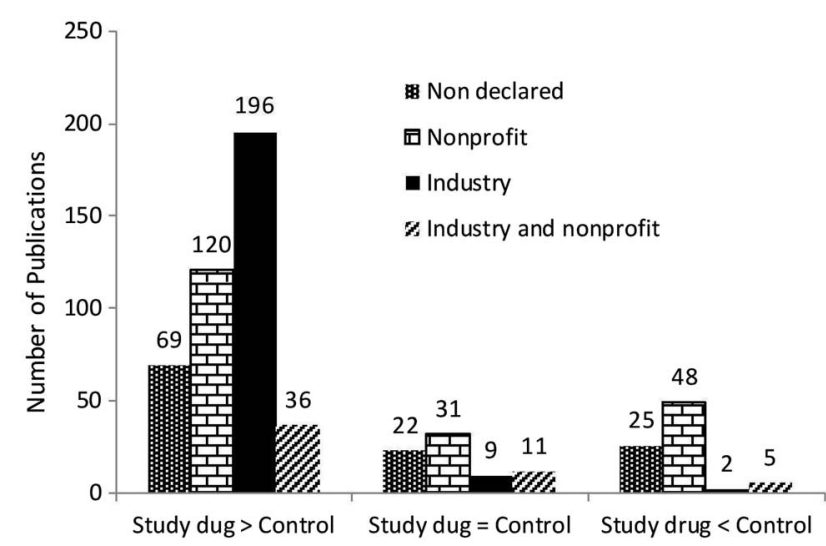

Figure 3 Study outcome and the source of funding.

\begin{tabular}{lll}
\multicolumn{2}{l}{ Table 3 } & QHES scores overtime and by funding sources \\
\hline \multirow{3}{*}{ Variable } & Level & $\begin{array}{l}\text { Mean QHES } \\
\text { score (SD) }\end{array}$ \\
\hline Study block & $1986-1991$ & $67.8(19.7)$ \\
& $1992-1997$ & $78.1(14.2)$ \\
& $1998-2003$ & $83.6(20.0)$ \\
& $2004-2009$ & $89.5(15.3)$ \\
Study funding & $2010-2015$ & $87.1(22.9)$ \\
& Non-profit & $80.4(18.6)$ \\
& Not declared & $78,2(21.1)$ \\
& Industry & $83.6(14.5)$ \\
& Industry and non-profit & $82.8(12.2)$ \\
\hline
\end{tabular}

becoming a frequently used criterion for decisionmaking in modern healthcare policy and patient access, including that related to cancer. ${ }^{16}$

There is a shift in the type journals where the cancer CEA is published. Most interestingly haematology/oncology and medicine-related journal categories existed until 2003. Since then, interest has relatively been shifting towards the healthcare sciences and services subject category journals. Generally, the shift is towards journals that specifically have the pharmacoeconomics research in their scope, regardless of subject category. One reason behind this could be that studies are increasingly conducted by specialised pharmacoeconomists and health economists, who are more familiar with journals that have interest in pharmacoeconomics. Another reason could be that authors may find that peer reviewers, in journals that focus on health economics, demonstrate a higher level of understanding of economic methods. In any case, it seems that health practitioners and practices will need to make sure to include specialised pharmacoeconomics and healthcare sciences and services journals in their readings and evidence search, despite the less relevant nature of the journals. Further, decision makers may need to make sure that systematic reviews, submitted to them for appraisal of interventions, include specialised databases relevant to pharmacoeconomics and healthcare sciences and services research. Studies between 1986 and 2003 were predominantly using prospective RCT data; from 2003 onwards, the retrospective design dominated, in relation to RCT and non-RCT data. Despite the general consideration of the prospective RCT design as the ideal source of data in comparative research, it is increasingly tempting to use the retrospective data. Retrospective data are inexpensive, reflect large sample sizes and, importantly, are readily available via increasingly large databases and open-access data resources. This added to recent technological advances in data collection and storage have enhanced the robustness of the retrospective data available. While prospective RCT data contributed in the literature more than prospective non-RCT data initially, the prospective non-RCT data were used more afterwards. Researchers seem to maintain an interest in the 
specific nature of the prospective data, but are decreasingly relying on RCT research, perhaps due to relatively expensive and more demanding nature of the latter. Such findings can be enlightening for future researchers, whereby the advantages of retrospective research can be used more by them. Also, decision makers, journal reviewers and editors, and the funding bodies can better appreciate the increasing role that retrospective research has in the provision of knowledge and evidence in the literature, especially given the relative inferior quality image that this research can easily have. Important, is that if decision makers and the health agencies and committees do look at the overtaking of the prospective type research by the retrospective one as a weakness in the literature and evidence it provides, these may need to put more efforts as part of their guidelines and requirements to particularly encourage researchers towards the former type of research.

The disclosure of funding sources has not generally increased over the study period, indicating a less than ideal transparent reporting of this relationship. This contradicts a literature study, by Buchkowsky and Jewesson, ${ }^{17}$ which indicated an improvement in the disclosure of funding sources in the literature over time, reaching $90 \%$ of publications. The Buchkowsky and Jewesson study, however, was to analyse clinical trials, and in five journals only. It seems that the disclosure of funding is more associated with RCTs than other types of studies. In addition, the five journals studied by Buchkowsky and Jewesson are some of the most prominent journals, with which strict guidelines in relation to the disclosure of funding are mostly implemented. To note, an observed lack in the disclosure of the funding source is just an observation of a literature characteristics and does not necessarily indicate a lack of transparency by authors. This is as if disclosing the financial sources behind a study is not necessarily a requirement by publishing journals. This is particularly true in the 1980s and 1990s, before many of the reporting guidelines were published, ${ }^{18-25}$ which may especially explain the lower disclosure rate reported by Buchkowsky and Jewesson in the same period.

The industry funding was significantly increasing, resulting in about similar overall prevalence to the nonprofit organisations funding by 2015. This is not consistent with the literature studies, by Lexchin $e t a l^{26}$ and Buchkowsky and Jewesson, ${ }^{17}$ whereby the prevalence of industry funding was reported to be lesser than other types of research funding. It is important to note here, however, that the Lexchin et al and Buchkowsky and Jewesson studies were simply focusing on the clinical trials research and up to the year 2000 only. The latter is actually in support of our study, where the size of the industry funding was overtaken by the other funding sources until early 2000s. Also, clinicians are perhaps less inclined to generally conduct CEA research when compared with clinical research, without the availability of industry funding.
The observation of an increasing trend of industry funding over time was consistent with the literature reports, by Clifford et $a l^{27}$ and Buchkowsky and Jewesson, ${ }^{17}$ in relation to clinical trials in five selected medical journals in the literature. This is also consistent with an increasing contribution percentage of industry funding reported, by Peppercorn et al, ${ }^{28}$ relating to breast cancer clinical trials publications in 10 journals, over 10 years follow-up.

The pharmaceutical industry authorship was at an increasing trend over time. This is supported by the Peppercorn et al report, ${ }^{28}$ where the industry authorship prevalence was found to increase over the 10 years of study follow-up, ending by 2003, but was not statistically significant.

There is an increase in consultation authorship over time and at a higher rate than the industry authorship. It is assumed, therefore, that the contraction of consultation firms by the pharmaceutical industry in relation to the cancer CEA is also increasing. The surprising thing in relation to the publications with paid consultation involvement is that in over quarter of them, the source of the study funding was not disclosed.

Changes in the quality status of economic evaluations overtime do not seem to be a factor behind changes in the above study's variables overtime. Included studies were in average of good quality. While the evaluations in the first study block were generally less than good, they were not poor, and few in number.

The majority of studies reported positive outcomes in favour of the study drug (ie, $73.1 \%$ of studies). A similar trend was also reported by Tungaraza and Poole, ${ }^{29}$ where positive findings were reported in $80 \%$ of clinical trials analysed in three psychiatric journals. It seems that authors are less likely to submit for publishing negative outcomes, and/or that journals are more likely to accept for publication the positive or significant findings. ${ }^{30-33}$ These are regardless of the source of funding. Here, disseminating negative research findings is an issue that gains traction, whereby journals are increasingly publishing negative results, including via specialised journals. Added to it is the pressure made on/by funding agencies for researchers to make all gathered data available. These efforts however are very recent and seem to have not yet affected the prevalence of reported positive/ negative outcomes overtime.

The economic outcome of a study intervention tended to more statistically significantly be positive in studies that are solely industry funded than in studies with non-declared or non-profit funding. It is important that, as discussed above, differences in study quality can be excluded as a confounding factor behind differences in the rate of positive outcomes among the different sources of study funding. The potential association between industry funding and reported study outcomes was extensively investigated in the literature. Large literature reviews were reported by Lundh $e t a l^{34}$ and Lexchin, ${ }^{35}$ suggesting an evidence that industry-funded 
studies produce biased results. These however only analysed clinical trials, with pharmacoeconomics being out of scope. A wider scope review of systematic reviews was reported by Schott et $a l^{36}$ where 26 publications were reported to have had investigated the possible relationship between the industry funding and favourable study results for interventions. In agreement with our study, 20 of these suggested that a statistically significant association existed. Nevertheless, these reports were of clinical trials only. There are other studies that especially evaluated the funding influence within the pharmacoeconomics research. ${ }^{7-10}$ 37-41 Although these also concluded a significant influence of industry funding, only four of them related to cancer. Friedberg et al $\vec{l}^{7}$ reported a reduced likelihood of unfavourable results in industry-funded studies, but this was in 1999 and only included three drug classes. The study by Hartmann et $a l^{8}$ also reported a significant association, but this was in 2003, only related to oncology. Jang et at reported the significant influence as well, but this only related to breast cancer therapies. Similar conclusion was also more recently reported by Valachis et $a l^{10}$ but only related to targeted therapies in oncology and only included clinical trials. To emphasise, the conclusion made in the current study relates to the isolated industry funding only, in separation from the mixed type of funding. This better suggests the isolated influence by the pharmaceutical companies. This separation was not taken in consideration by the relevant literature, except for the study by Buchkowsky and Jewesson. ${ }^{17}$ But the association with both as reported in their study was not statistically significant. This is consistent with the current study, in relation to the mixed funding.

There are several potential reasons behind this connection between industry funding and positive study results. There is evidence that pharmaceutical companies often influence the study methodology to their advantage ${ }^{42-45}$ For example, the use of placebos instead of alternative controls was found to be more common in industry-funded studies. ${ }^{32}$ Another reason is that up to $50 \%$ of the research conducted by pharmaceutical companies remains unpublished, if did not produce significant positive results. ${ }^{30-32}$ Even before studies are conducted, a pharmaceutical company may selectively fund comparative research on drugs that they consider to be superior over competition. ${ }^{7}$

There are already several published research reporting guidelines for reporting the different aspects discussed in this study, ${ }^{18-25}$ including in relation to the pharmacoeconomics research, that is, CHEERS. Results in the current study, however, suggest that more effort by reviewers and editors of CEA publishing journals should be put towards adhering to these guidelines, perhaps via rejecting to publish (or review) articles that do not clearly disclose standardised reporting details, which is what editors of several impact journals reported to already do, as appears in the report 'Uniform Requirements for Manuscripts Submitted to Biomedical
Journals: Writing and Editing for Biomedical Publication', by the International Committee of Medical Journal Editors. ${ }^{46} 47$

There are several strengths in the current study. The reviewed studies are not from selected journals, which enhance the external validity of results. Also, the analysed studies represented $100 \%$ of the found literature. In addition, the 30-year duration of follow-up in this study is sufficient and larger than in similar literature studies. Further, this is the first study to explore the CEA literature of cancer therapies, and in relation to the association between industry funding and study results, this is the most comprehensive. Moreover, an assessment of the quality studies was conducted for the exclusion of this as a confounding factor.

There are several limitations with our study. While it is acknowledged that studies of different types of cancer or chemotherapies have different levels of priority for decision makers, the scope of the present study is in relation to the comparative literature studies in general, with no special interest given to any particular type of cancer or therapy. Restricting search to English literature is another limitation in the study. The authors do not have the resources to translate all the non-English research literature that generated from a non-restricted search, which include, for example Chinese, French, German, Japanese and Russian. This is when including certain non-English language literature while excluding others is not justified. Nevertheless, this is not a therapeutics review where looking at every relevant publication is required and, in any case, this study's observations are limited to the scope of the restricted search, For our purpose, the English-based literature is considered representative of scientific literature. Moreover, while comprehensive literature search was indeed conducted in this study, relevant studies could have been also explored in other literature databases that may include Global Health, Health Economic Evaluation Database, Cost-effectiveness Analysis Registry, Open Grey and Information technology Assessment international. This study does not review the literature at the therapy level, where no conclusions are made in relation to use of therapies in practices and the evidence. Ongoing research, however, does exist in relation to assessing $\mathrm{CE}$ of chemotherapies and making recommendations for best evidence-based use in clinical practices. ${ }^{48}$ Further to limitations, searching additional MeSH terms to those in the study and/or additional aggregations of them is always possible and may generate additional studies. Also a limitation is that while different journals have varying publication criteria, all journals were weighted equally in this study, which can be associated with bias. This publication bias is anticipated to be minimised, however, due to how thorough the search strategy was, which included 100 s of articles of all types, from all settings, from all perspectives, from all journals, in relation to all therapies for all cancers, and over a very long duration. In addition, our selection of 5 time periods was arbitrary, and 
other methods could yield different results. Nevertheless, the number of time points we used is more than that used in similar published research. ${ }^{49}$

\section{CONCLUSION}

Literature journals are gradually more interested in publishing CEA investigations, particularly in journals that clearly focus on the health economic research. Our findings also indicate that researchers are increasingly relying on less than ideal source of data (ie, retrospective data), when compared with the prospective. The industry funding of research is prevalent and increasing over time. The industry authorship is also increasing in publications, but to a lesser extent than that by paid consultation firms. In this study, we suggest that the evidence that a CE evaluation of cancer therapies may not report a result that is not positive is stronger with sole pharmaceutical industry funding than with other funding sources. The findings in the current study enable several opportunities for the researchers, journal editors and reviewers, and the decision makers to enhance the $\mathrm{CE}$ literature in cancer as they conduct, revise and appraise research and synthesise evidence.

Contributors DA-B conceived and designed the study, participated in data collection and analyses, interpreted results and drafted the manuscript. MA and RA-0 performed data collection and revised the manuscript. All authors read and approved the final manuscript.

Competing interests None declared.

Provenance and peer review Not commissioned; externally peer reviewed.

Data sharing statement No additional data are available.

Open Access This is an Open Access article distributed in accordance with the Creative Commons Attribution Non Commercial (CC BY-NC 4.0) license, which permits others to distribute, remix, adapt, build upon this work noncommercially, and license their derivative works on different terms, provided the original work is properly cited and the use is non-commercial. See: http:// creativecommons.org/licenses/by-nc/4.0/

\section{REFERENCES}

1. Cancer, Fact Sheet. World Health Organization. 2015. http://www. who.int/mediacentre/factsheets/fs297/en/ (accessed 13 Mar 2016).

2. American Cancer Society. Cancer facts \& figures 2013. Atlanta: American Cancer Society, 2013.

3. Ahmad AS, Ormiston-Smith N, Sasieni PD. Trends in the lifetime risk of developing cancer in Great Britain: comparison of risk for those born from 1930 to 1960. Br J Cancer 2015;112:943-7.

4. Siddiqui M, Rajkumar SV. The high cost of cancer drugs and what we can do about it. Mayo Clin Proc 2012;87:935-43.

5. Cancer Therapies. Technologies and Global Markets. Bcc Research -Market Forecasting. 2008. http://www.bccresearch.com/ market-research/healthcare/cancer-therapies-market-hlc027b.html (accessed 13 Mar 2016).

6. Fojo T, Grandy C. How much is a life worth: Cetuximab, non small cell lung cancer, and the $\$ 440$ billion question. J Natl Cancer Inst 2009;102:1044-8.

7. Friedberg M, Saffran B, Stinson TJ, et al. Evaluation of conflict of interest in economic analyses of new drugs used in oncology. JAMA 1999;282:1453-7.

8. Hartmann M, Knoth H, Schulz D, et al. Industry-sponsored economic studies in oncology vs studies sponsored by nonprofit organisations. Br J Cancer 2003;89:1405-8.

9. Jang S, Chae YK, Haddad T, et al. Conflict of interest in economic analyses of aromatase inhibitors in breast cancer: a systematic review. Breast Cancer Res Treat 2010;121:273-9.
10. Valachis A, Polyzos NP, Nearchou A, et al. Financial relationships in economic analyses of targeted therapies in oncology. $\mathrm{J}$ Clin Oncol 2012;30:1316-20.

11. Qatar University Library. Qatar University. 2015. http://library.qu.edu. qa/ (accessed 4 Dec 2015)

12. Design dilemma. The debate over using placebos in cancer clinical trials. National Cancer Institute. National Institute of Health. 2011. https://www.cancer.gov/about-cancer/treatment/research/ placebo-clinical-trials (accessed 5 Nov 2016).

13. Mishra D, Nair SR. Systematic literature review to evaluate and characterize the health economics and outcomes research studies in India. Perspect Clin Res 2015;6:20-33.

14. Marshall D, Donald F, Lacny S, et al. Assessing the quality of economic evaluations of clinical nurse specialists and nurse practitioners: a systematic review of cost-effectiveness. NursingPlus Open 2015;1:11-17.

15. Tran B, Nong V, Maher R, et al. A systematic review of scope and quality of health economic evaluation studies in Vietnam. PLOS ONE 2014;9:e103825.

16. Oncology drug development and value-based medicine. Quintiles. 2014. http://www.quintiles.com/library/white-papers/ oncology-drug-development-and-valuebased-medicine (accessed 5 Aug 2016).

17. Buchkowsky SS, Jewesson PJ. Industry sponsorship and authorship of clinical trials over 20 years. Ann Pharmacother 2004;38: 579-85.

18. Schulz KF, Altman DG, Moher D, for the CONSORT Group CONSORT 2010 Statement: updated guidelines for reporting parallel group randomised trials. BMJ 2010;340:c332.

19. Moher D, Liberati A, Tetzlaff J, et al. Preferred Reporting Items for Systematic reviews and Meta-analyses: the PRISMA statement. BMJ 2009;339:b2535

20. von Elm E, Altman DG, Egger M, et al. Strengthening the reporting of observational studies in epidemiology (STROBE) statement: guidelines for reporting observational studies. BMJ 2007;335: 806-8.

21. Tong A, Flemming K, Mclnnes E, et al. Enhancing transparency in reporting the synthesis of qualitative research: ENTREQ. BMC Med Res Methodol 2012;12:181.

22. Gagnier JJ, Kienle G, Altman DA, et al. the CARE Group. The CARE guidelines: consensus-based clinical case reporting guideline development. J Med Case Rep 2013:7:223.

23. Lang TA, Altman DG. Basic statistical reporting for articles published in biomedical journals: the 'statistical analyses and methods in the published literature' or the 'SAMPL guidelines'. In: Smart P, Maisonneuve H, Polderman A, editors. Science editors' handbook. UK: European Association of Science Editors, 2013:175-82.

24. Davidoff F, Batalden $P$, Stevens D, et al. Publication guidelines for quality improvement in health care: evolution of the SQUIRE project. BMJ 2009;338:a3152.

25. Husereau D, Drummond M, Petrou S, et al. Consolidated Health Economic Evaluation Reporting Standards (CHEERS) statement. Value Health 2013;16:e1-5.

26. Lexchin J, Bero LA, Djulbegovic B, et al. Pharmaceutical industry sponsorship and research outcome and quality: systematic review. BMJ 2003;326:1167-70.

27. Clifford TJ, Barrowman NJ, Moher D. Funding source, trial outcome and reporting quality: are they related? Results of a pilot study. BMC Health Serv Res 2002;2:18.

28. Peppercorn J, Blood E, Winer E, et al. Association between pharmaceutical involvement and outcomes in breast cancer clinical trials. Cancer 2007;109:1239-46.

29. Tungaraza T, Poole R. Influence of drug company authorship and sponsorship on drug trial outcomes. Br J Psychiatry 2007;191: 82-3.

30. Lee K, Bacchetti P, Sim I. Publication of clinical trials supporting successful new drug applications: a literature analysis. PLoS Med 2008;5:e191.

31. Rising K, Bacchetti $P$, Bero L. Reporting bias in drug trials submitted to the Food and Drug Administration: review of publication and presentation. PLOS Med 2008;5:e217.

32. Turner $\mathrm{EH}$, Matthews $\mathrm{AM}$, Linardatos $\mathrm{E}$, et al. Selective publication of antidepressant trials and its influence on apparent efficacy. N Engl J Med 2008;358:252-60.

33. Melander $\mathrm{H}$, Ahlqvist-Rastad J, Meijer G, et al. Evidence b(i)ased medicine-selective reporting from studies sponsored by pharmaceutical industry: review of studies in new drug applications. BMJ 2003;326:1171-3.

34. Lundh A, Sismondo S, Lexchin J, et al. Industry sponsorship and research outcome. Cochrane Database Syst Rev 2012;12: MR000033. 
35. Lexchin J. Those who have the gold make the evidence: how the pharmaceutical industry biases the outcomes of clinical trials of medications. Sci Eng Ethics 2012;18:247-61.

36. Schott $\mathrm{G}$, Pachl H, Limbach $\mathrm{U}$, et al. The financing of drug trials by pharmaceutical companies and its consequences. Dtsch Arztebl Int 2010;107:279-85

37. Baker CB, Johnsrud MT, Crismon ML, et al. Quantitative analysis of sponsorship bias in economic studies of antidepressants. $\mathrm{Br}$ J Psychiatry 2003;183:498-506.

38. Peura PK, Martikainen JA, Purmonen TT, et al. Sponsorshiprelated outcome selection bias in published economic studies of triptans: systematic review. Med Decis Making 2012;32: 237-45.

39. Bell CM, Urbach DR, Ray JG, et al. Bias in published cost effectiveness studies: systematic review. BMJ 2006;332: 699-703.

40. Miners $\mathrm{AH}$, Garau M, Fidan D, et al. Comparing estimates of cost effectiveness submitted to the National Institute for Clinical Excellence (NICE) by different organisations: retrospective study. BMJ 2005;330:365-8.

41. Franco $\mathrm{OH}$, Peeters $\mathrm{A}$, Looman CWN, et al. Cost effectiveness of statins in coronary heart disease. J Epidemiol Community Health 2005;59:927-33.

42. Katz KA, Karlawish JH, Chiang DS, et al. Prevalence and factors associated with use of placebo control groups in randomized controlled trials in psoriasis: a cross-sectional study. J Am Acad Dermatol 2006;55:814-22.

43. Waldinger MD, Schweitzer DH. Premature ejaculation and pharmaceutical company-based medicine: the dapoxetine case. $J$ Sex Med 2008:5:966-97.

44. Hill KP, Ross JS, Egilman DS, et al. The ADVANTAGE seeding trial: a review of internal documents. Ann Intern Med 2008;149:251-8.

45. Nieto A, Mazon A, Pamies R, et al. Adverse effects of inhaled corticosteroids in funded and nonfunded studies. Arch Intern Med 2007; 167:2047-53.

46. Uniform requirements for manuscripts submitted to biomedical journals: writing and editing for biomedical publication. International Committee of Medical Journal Editors. 2008. http://www.icmje.org/ recommendations/archives/2008_urm.pdf (accessed 4 Dec 2015).

47. Recommendations for the conduct, reporting, editing and publications of scholarly work in medical journals. International Committee of Medical Journal Editors. 2014. http://www.icmje.org/ icmje-recommendations.pdf (accessed 13 Mar 2015).

48. Rudy N, Chittenden $\mathrm{H}$, Fisher D, et al. A systematic review of the cost-effectiveness of chemotherapy regimens. Pharmacy and Nursing Student Research and Evidence-Based Medicine Poste Session-Paper 67. 2015. http://digitalcommons.cedarville.edu/ pharmacy nursing poster session/67 (accessed 5 Nov 2016).

49. Ungar WJ, Santos MT. Trends in paediatric health economic evaluation: 1980 to 1999. Arch Dis Child 2004;89:26-9. 